\title{
Progressive balloon dilatation following hepaticojejunostomy improves outcome of bile duct stricture after iatrogenic biliary injury
}

\author{
Zhu-lin Luo ${ }^{1,2 \dagger}$, Long Cheng ${ }^{1 \dagger}$, Jian-dong Ren ${ }^{1}$, Li-jun Tang ${ }^{1}$, Tao Wang ${ }^{1}$ and Fu-zhou Tian ${ }^{\text {* }}$
}

\begin{abstract}
Background: latrogenic biliary stricture (IBS) is a disastrous complication of cholecystectomy. Although the endoscopic treatments are well accepted as initial attempts for IBS, surgical hepaticojejunostomy (HJ) is often necessary for a considerable proportion of patients. However, the anastomotic stricture after $\mathrm{HJ}$ also occurs.

Methods: In the present study, a new procedure, progressive balloon dilation following HJ (HJPBD), was designed and utilized in the IBS treatment. We retrospectively compared HJPBD with the traditional HJ in term of the outcomes when used for IBS treatment.

Results: Between January 1997 and December 2009, 112 patients with IBS attributed to cholecystectomy enrolled in our hospital were treated with surgical reconstruction with either HJ $(n=58)$ or HJPBD $(n=54)$. Of the 58 patients in HJ group, 48 patients (82.8\%) had a successful outcome, while 52 out of 54 patients (96.3\%) in HJPBD group achieved success. The successful surgical reconstruction rates were significantly different between these two groups, with a further improved outcome in patient undergone progressive balloon dilation following $\mathrm{HJ}$. Additionally, 8 of the 10 failure cases in HJ group were successfully rescued by HJPBD procedure.
\end{abstract}

Conclusions: Our findings suggest that the new procedure of HJPBD could be successfully applied to IBS patients, and significantly improve the outcome of IBS reconstruction.

Keywords: latrogenic biliary strictures, Cholecystectomy, Balloon dilation, Hepaticojejunostomy

\section{Background}

Bile duct injury (BDI) occurs in a non-negligible proportion of patients who undergo cholecystectomy, especially laparoscopic cholecystectomy (LC) [1-3]. Delayed detection and inappropriate treatment of BDI post cholecystectomy are often complicated by biliary strictures. This type of bile duct stricture is treated non-surgically or by surgical hepaticojejunostomy (HJ). Endoscopic or radiologic interventions have often been initially attempted, but in vain in a considerable number of patients because of failure of guide-wire passage through the stricture site [4-6]. Even when the endoscopic procedure or radiologic interventions are successful, strictures recur in a considerable

\footnotetext{
* Correspondence: tfz30061@yahoo.com.cn

${ }^{\dagger}$ Equal contributors

'Department of General Surgery, General Hospital of Chengdu Military

Command, Chengdu, Sichuan Province, People's Republic of China

Full list of author information is available at the end of the article
}

number of patients. So, at these circumstances, surgical hepaticojejunostomy become necessary.

The outcome of $\mathrm{HJ}$ for iatrogenic biliary stricture (IBS) is usually favorable, but a small proportion of patients suffer anastomotic stricture and recurrent bile duct stricture $[7,8]$. Thus, to reduce the occurrence rate of anastomotic stricture or recurrent bile duct stricture, several issues regarding HJ for IBS have been proposed and still waiting for solutions $[9,10]$. The questions that are often raised include: (1) when is the optimal time for operation (earlier or later?); and (2) which condition gives higher successful rate of $\mathrm{HJ}$ (disappearance of inflammatory edema or dilation of the proximal bile duct?). At present, $\mathrm{HJ}$ for IBS is often performed after the subsidence of inflammation and the dilation of proximal bile duct. The long-term success rates of $\mathrm{HJ}$ for IBS are reported ranging from $80 \%-90 \%$ $[11,12]$. Although only a small proportion of patients suffer failure, it remains unacceptable, because of the repeated

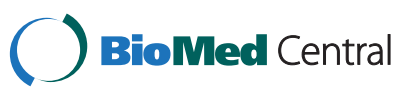

(C) 2013 Luo et al.; licensee BioMed Central Ltd. This is an Open Access article distributed under the terms of the Creative Commons Attribution License (http://creativecommons.org/licenses/by/2.0), which permits unrestricted use, distribution, and reproduction in any medium, provided the original work is properly cited. 
cholangitis, biliary cirrhosis or even death just caused by what seems to be a simple operation, cholecystectomy.

In order to further improve the outcome of HJ for IBS, since 1997, we have designed and utilized a new procedure, progressive balloon dilatation following HJ (HJPBD), which was performed no mattering whether the bile duct is dilated or not [13]. In the current study, we retrospectively compare traditional $\mathrm{HJ}$ with $\mathrm{HJPBD}$, in term of the technical complications and long-term outcome of patients with IBS. Our data showed that the new procedure HJPBD significantly improves outcome of IBS repair compared with traditional surgical procedures.

\section{Methods \\ Patients}

Between January 1997 and December 2009, 208 patients diagnosed with biliary strictures post-cholecystectomy were enrolled in a tertiary level referral hospital in China. In addition to ultrasonogram of the abdomen, endoscopic retrograde cholangiography, magnetic resonance cholangiography or percutaneous transhepatic cholangiography were performed for the assessment of strictures. Some patients had multiple cholangiograms. Ninety six patients with IBS who were managed conservatively or with endoscopic or radiological intervention as definitive treatment and achieved well outcome were excluded from this analysis. The remaining 112 patients who failed to achieve well outcome by endoscopic or radiological intervention or other conservative treatment were prepared to perform surgical reconstruction. Whether the traditional HJ or the new designed procedure HJPBD was performed was dependent on the maximal diameter of the upper segments of bile duct strictures. Accordingly, 58 patients with the maximal diameter of the upper segments more than 1.0 $\mathrm{cm}$ were performed with traditional $\mathrm{HJ}$, and 54 patients with that less than $1.0 \mathrm{~cm}$ were performed with the new designed procedure HJPBD. All of these 112 patients underwent surgical reconstruction in the same Center of General Surgery of this hospital.

Ethical approval was given by the medical ethics committee of General Hospital of Chengdu Military Command area. All of the patients in the study were informed the possible complications brought by the surgical hepaticojejunostomy, and those patients underwent hepaticojejunostomy as well as balloon insert and fixation were informed the possible discomfort associated with the inserted balloons. The consent was obtained routinely before the surgical procedure and not for anything specifically related to this study.

\section{Surgical procedure}

Roux-en-Y HJ was the standard surgical repair. In patients treated with abdominal drainages, definitive operations were performed after 1 month' drainages. During the operation, scars and granulation tissues of the injured bile duct were dissected, the distal end of the injured bile duct was closed, and the intact proximal end of the bile duct was opened with "Y"-shape incision which extended to the left and right hepatic bile ducts. Through the "Y" incision, three duct branches could be seen (two of the right hepatice bile ducts and one of the left hepatic bile duct). The reconstructed hepatic bile duct was then sutured with the jejunum by end-toside anastomosis. A " $\mathrm{T}$ " stent was placed into the left and right hepatic bile ducts and sewed on internal wall of the bile ducts to ensure its position for 6 months. In HJPBD group, two trans-anastomotic balloons were inserted and fixed with the "T" stent, Figures 1 and 2.

\section{Progressive balloon dilation}

The balloon (Cook Inc., Bloomington, IN, USA) placed at the anastomosishas a length of $30-\mathrm{mm}$ in column shape with a diameter of $1.8 \mathrm{~mm}$ and $10 \mathrm{~mm}$ before and after insufflation, respectively. One week after operation, the balloon was insufflated in a slow pace to avoid laceration to the bile duct. Dilation was done 4 times each day and maintained for 2 to 4 hours each time. The initial volume of insufflations varied due to different severity of biliary stricture. The volume and pressure required for insufflation were mainly based on the subjective tolerance of the pain caused by dilatation, and gradually reached to the maximal volume of about $10 \mathrm{ml}$ within 2 months post-operation. During the third month post-operation, the balloon insufflation was kept with the maximal volume

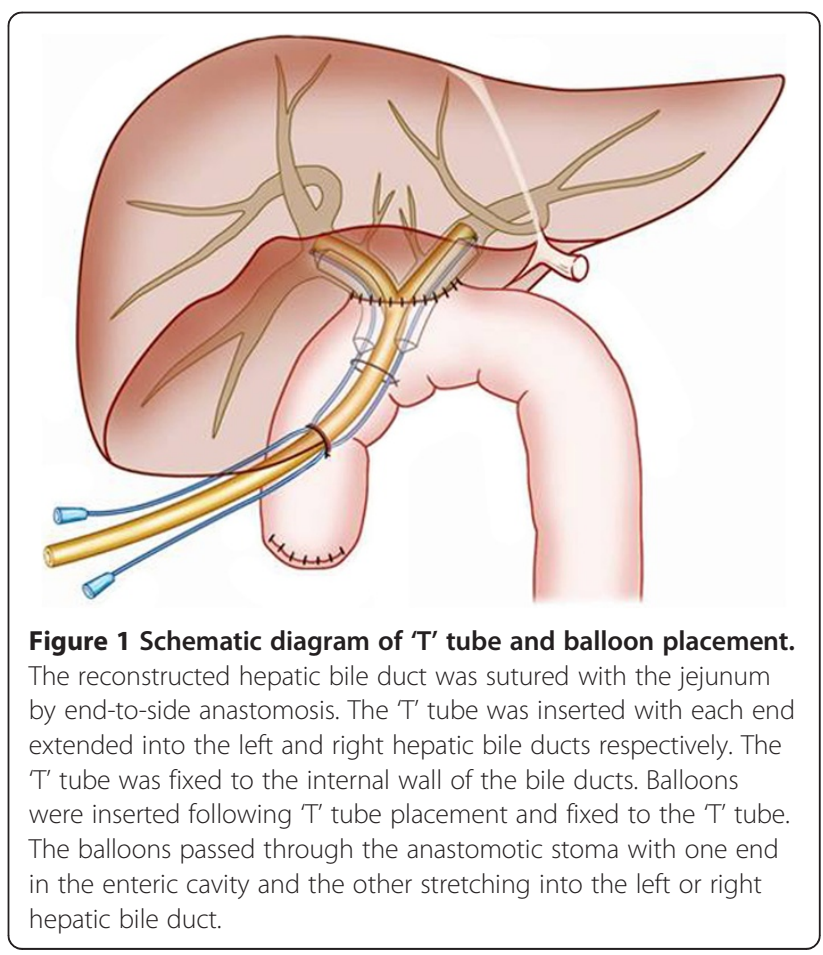




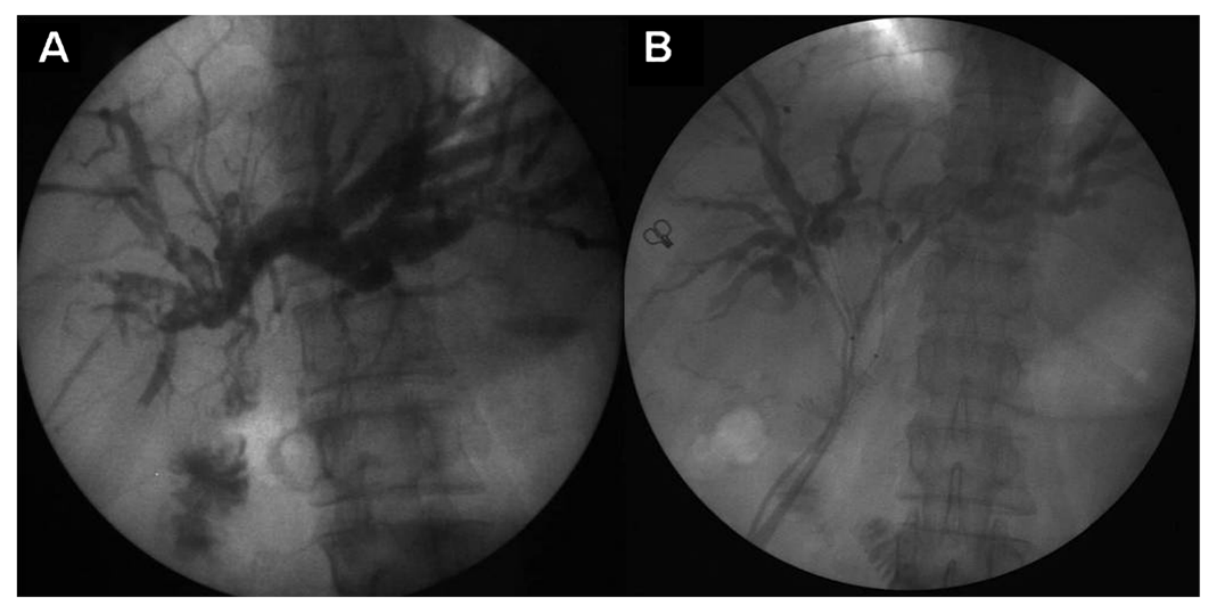

Figure 2 Images of biliary system before and after HJPBD. A: Before HJPBD, the X-ray photography with cholangiography showed that the lesions located at the common hepatic duct stump with the ceiling of the confluence was destroyed; $\mathbf{B}$ : Two months after HJPBD, the X-ray photography with cholangiography showed that the two balloons were still at their positions, both passing through the anastomotic stoma with one end in the enteric cavity and the other stretching into the left or right hepatic bile duct. HJPBD: progressive balloon dilation following hepaticojejunostomy.

for 4 hours each time and 4 times per day. In this way, the bile duct was kept in a dilated state in $2 / 3$ time daily, and in the rest of time the balloon was decompressed to let the bile draining. The patients were trained to be familiar with the performance of dilatation during hospitalization, and the dilatation should be performed by patients themselves out of hospitalization. At the end of the third month after surgical reconstruction, the " $\mathrm{T}$ " stent and decompressed balloon were removed after checking the anastomosis junction and portal bile duct using cholangiography.

\section{Follow-up data and evaluation criteria}

Follow-up information was collected by outpatient visits, mailed questionnaires, and telephonic interviews. Followup evaluation was done by clinical history and examination, liver function tests (LFT), and US. Patients who were eligible for a minimum follow-up of 2 years at the time of analysis (Dec 2011) were included in the study. Outcome of surgical repair was stratified into four grades as previously described by McDonald [14]: Grades A (asymptomatic, normal LFT), B (asymptomatic, mild LFT derangement), C (pain, cholangitis defined as fever with jaundice, and abnormal LFT), and D (surgical revision or dilatation required). Patients with grade A and B were classified as treatment successes, while patients with grade $\mathrm{C}$ and $\mathrm{D}$ were classified as failures.

\section{Statistical analysis}

Statistical analyses were performed using SPSS version 13.0 for Windows (Statistical Package for the Social Sciences; SPSS, Munich, Germany). Continuous variables in the 2 groups were analyzed with a Student $t$ test or MannWhitney $U$ test according to the continuous data with normal or non-normal distributions. Differences in categorical variables were analyzed by $\chi^{2}$ and Fisher's exact tests. A 2 -tailed $P$ value $<0.05$ was considered statistically significant.

\section{Results}

\section{Patient characteristics}

One hundred and twelve patients with IBS were included in the present study. There was no difference in baseline characteristics between HJ and HJPBD groups, Table 1 . Of them 51 patients were males and 61 were females aged from 13 to 74 years old. In the 112 patients, a half of patients (56 out of 112) have not suffered episode of cholangitis indicating by lack of chills, fever and jaundice. Of the 112 IBS patients, 29 had undergone open cholecystectomy $(\mathrm{OC})$ and 83 had undergone laparoscopic cholecystectomy (LC).

Bile duct injuries were observed in 66 patients within 7 days post-cholecystectomy, and had been initially treated with $\mathrm{T}$ tube drainage ( $\mathrm{n}=23$ ), bile duct end-toend anastomosis $(n=31)$ or local tissue repairs $(n=12)$. The strictures were detected at 3 to 43 months after cholecystectomy. Ninety one patients with stricture were undergone at least one attempt of ERCP or PTC. Bile duct strictures were classified into five types according to their location in relationship to the hepatic duct bifurcation as previously described by Bismuth [15].

\section{Outcomes of patients}

Median follow-up was 52 (24- 156) months. There was not any significant difference between HJ and HJPBD groups regarding to operation duration time, bleeding volume, anesthesia, etc. Outcome of surgical repair was 
Table 1 Baseline characteristics

\begin{tabular}{|c|c|c|}
\hline & $\mathrm{HJ}$ & HJPBD \\
\hline $\mathrm{N}$ & 58 & 54 \\
\hline Sex, F/M & $33 / 25$ & $28 / 26$ \\
\hline Age, years (mean \pm SD) & $42.6 \pm 9.4$ & $39.8 \pm 8.5$ \\
\hline Cholecystectomy, OC/LC & $16 / 42$ & $13 / 41$ \\
\hline Early detection of bile duct injury & 36 & 30 \\
\hline Episode of cholangitis & 29 & 27 \\
\hline $\begin{array}{l}\text { Median time from cholecystectomy to } \\
\text { biliary stricture, months }\end{array}$ & 9.5 & 11.0 \\
\hline \multicolumn{3}{|l|}{ Type of biliary stricture } \\
\hline Type I & 14 & 14 \\
\hline Type $\|$ & 13 & 9 \\
\hline Type IIla & 10 & 11 \\
\hline Type IIla & 18 & 19 \\
\hline Type IV & 3 & 1 \\
\hline Undergone ERCP or PTC before surgery & 47 & 44 \\
\hline
\end{tabular}

Notes: There was no difference in baseline characteristics between $\mathrm{HJ}$ and HJPBD groups.

stratified into four grades as previously described by McDonald [14], and the patients with grade A and B were classified as treatment successes, while patients with grade $\mathrm{C}$ and $\mathrm{D}$ were classified as failures. Of the 58 patients in HJ group, 48 patients $(82.8 \%)$ had successful outcome, while 52 out of 54 patients (96.3\%) in HJPBD group achieved success. Moreover,in long-term follow-up, patients achieving grades A (asymptomatic, normal LFT) account more in HJPBD group than that in HJ group, Table 2. Statistic analysis showed that the successful surgical reconstruction rates were significantly different between these two groups $(\mathrm{p}<0.05)$, with a further improved outcome in patient undergone progressive balloon dilation following $\mathrm{HJ}$.

Additionally, of the 10 failure cases in $\mathrm{HJ}$ group, 1 patient suffered death (due to repeated episodes of cholangitis and subsequent liver cirrhosis), and the other 9 patients received HJPBD procedure with 8 patients successfully

Table 2 General outcome of patients

\begin{tabular}{llll}
\hline & & HJ & HJPBD \\
\hline Successes & Grade A & 36 & 45 \\
& Grade B & 12 & 7 \\
Failures & Grade C & 4 & 1 \\
& Grade D & 6 & 1 \\
Total & 58 & 54 &
\end{tabular}

Notes: Outcome of surgical repair was stratified into four grades as previously described by McDonald [14]: Grades A (asymptomatic, normal LFT), B (asymptomatic, mild LFT derangement), $C$ (pain, cholangitis defined as fever with jaundice, and abnormal LFT), and D (surgical revision or dilatation required). Patients with grade $A$ and $B$ were classified as treatment successes, while patients with grade $C$ and $D$ were classified as failures. rescued. Overall the procedure of HJPBD failed in 3 patients, of whom one received PTC, one underwent second HJPBD and another underwent transplantation.

The occurrence of biliary complications after surgical reconstruction was also analyzed. While the incidences of cholangitis, bile leakage and biliary bleeding were comparable between the two groups, the restenosis occurred more frequently in $\mathrm{HJ}$ group than in HJPBD group (12.07\% versus $1.85 \%)$, Table 3 . The results suggested that the performance of the new procedure could reduce the incidence of bile duct restenosis without increasing the other biliary complications.

\section{Discussion}

Since the widespread of LC, iatrogenic biliary stricture (IBS) due to cholecystectomy appears more frequently, and its treatment becomes a challenging topic for hepatobiliary surgeons. Although endoscopic treatments play an important role in the IBS therapy, a considerable portion of patients still need surgical hepaticojejunostomy (HJ) [16]. At present, HJ for IBS is often performed after the subsidence of inflammation and the dilation of proximal bile duct $[15,17]$. Subsidence of inflammation is necessary for operation, and one month is often sufficient for the inflammation recovery through appropriate treatment. However, it remains to be addressed how to gain satisfactory dilation and whether it is feasible to perform $\mathrm{HJ}$ without dilation of proximal bile duct.

It is generally believed that the extra-hepatic bile duct with smaller diameter is more prone to be injured during cholecystectomy $[18,19]$. For these patients, the success rate of $\mathrm{HJ}$ is relatively lower if the proximal bile duct segments of the stenosis are not dilated, circumstances that are present in more than half of patients. So it is necessary to take proper steps to gain satisfactory dilation for these patients. However, it is difficult to obtain a satisfactory dilated bile duct $(>10 \mathrm{~mm})$ in clinical practice. As forceful dilation of bile duct during operation is not practical since it is easy to lacerate the bile duct, 3 to 6 months' passive dilatation before operation is recommended to make it easy for anastomosis and to reduce the recurrence rate of strictures [20]. However, the long time waiting for the dilation is sometimes unacceptable, and during this period, more treatments will be proposed. Even if patients could endure to the end of the procedure for the dilation of the bile duct,

Table 3 Biliary complications post surgical reconstruction

\begin{tabular}{llll}
\hline Complications & HJ $(\mathbf{n}=\mathbf{5 8})$ & HJPBD $(\mathbf{n = 5 4 )}$ & P value \\
\hline Cholangitis & 5 & 2 & $>0.05$ \\
Bile leak & 3 & 4 & $>0.05$ \\
Biliary bleeding & 1 & 1 & $>0.05$ \\
Restenosis & 7 & 1 & $<0.01$ \\
\hline
\end{tabular}


there are still a considerable number of patients that could not be beneficiated with satisfactory dilation of bile ducts.

To avoid the passive waiting for the dilation of bile duct before $\mathrm{HJ}$, we designed a positive dilation procedure after $\mathrm{HJ}$, based on the principle of subcutaneous balloon dilation to obtain skin flap in the facial orthopedic operation. In the current study, we performed $\mathrm{HJ}$ after the subsidence of inflammation, no mattering whether the bile ducts were dilated or not dilated, and simultaneously inserted a flexible balloon, which could progressively dilate the anastomotic site. With a follow-up of 2 to 13 years, we observed a better long-term outcome for IBS treatment with this new procedure comparing with traditional HJ. We found that the anastomosis site can be dilated enough by progressively dilating with the balloon for three months after surgery. Additionally, we found the anastomosis site would not shrunk back after dilated, probably because of the balloon prop during the period of wound healing and tissue remodeling at the site of anastomosis. However, this exciting outcome need to be further confirmed by following randomized-controlled trial which had been initiated by us. Meanwhile, the role and mechanisms of progressive balloon dilation in bile duct tissue remodeling should be further investigated in animal models.

Complications of progressive balloon dilation include balloon loosing, broken and air leaking, which all influence the outcome of IBS treatment. Therefore, a careful caution should be taken during the procedure. Since subjective turgid feeling is the best indication to control the volume for balloon insufflation, patients should be informed how to do balloon insufflations. Patients could insufflate balloon by themselves and control insufflation volume and pressure based on their own feelings. In addition, patients should know how to take care of the balloon to avoid slippage or damage to it.

\section{Conclusions}

In conclusion, our findings suggest that the new procedure, i.e. earlier hepaticojejunostomy followed by progressive balloon dilation, could be successfully applied to IBS patients and significantly improved the outcome of IBS reconstruction. Based on our obseration, we tentatively proposed that the optimal operation timing for successful IBS reconstruction may be as early as the subsidence of inflammation, instead of waiting for the dilatation of the proximal segment of stricture.

\section{Consent}

Written informed consent was obtained from the patients for publication of this report and any accompanying images.

\section{Competing interests}

The authors declare that they have no competing interests.

\section{Authors' contributions}

ZLL and LC contributed equally to the design of the study and direction of its implementation. FZT conceived and designed the experiments and supervision of the field activities. ZLL and LC carried out the literature review and prepared the Materials and Methods and the Discussion sections of the text. JDR and TW conducted the data analysis. LJT critically revised of the manuscript for important intellectual content. All authors read and approved the final version of the manuscript.

\section{Acknowledgements}

The authors thank Rafael Nunez Nateras, M.D. of Mayo Clinic Arizona for carefully reviewing the paper and thoughtfully comments.

\section{Author details}

'Department of General Surgery, General Hospital of Chengdu Military Command, Chengdu, Sichuan Province, People's Republic of China. ${ }^{2}$ Graduate School, Third Military Medical University, Chongqing, People's Republic of China.

Received: 22 December 2012 Accepted: 17 April 2013

Published: 22 April 2013

\section{References}

1. Savader SJ, Lillemoe KD, Prescott CA, Winick AB, Venbrux AC, Lund GB, Mitchell SE, Cameron JL, Osterman FA Jr: Laparoscopic cholecystectomy related bile duct injuries: a health and financial disaster. Ann Surg 1997, 225(3):268-273.

2. Pesce A, Portale TR, Minutolo V, Scilletta R, Li Destri G, Puleo S: Bile duct injury during laparoscopic cholecystectomy without intraoperative cholangiography: a retrospective study on 1,100 selected patients. Dig Surg 2012, 29(4):310-314.

3. Richardson MC, Bell G, Fullarton GM: Incidence and nature of bile duct injuries following laparoscopic cholecystectomy: an audit of 5913 cases. Br J Surg 1996, 83(10):1356-1360.

4. Jabłońska B, Lampe P: latrogenic bile duct injuries: etiology, diagnosis and management. World J Gastroenterol 2009, 15(33):4097-4104.

5. Kassab C, Prat F, Liguory C, Meduri B, Ducot B, Fritsch J, Choury AD, Pelletier $\mathrm{G}$ : Endoscopic management of post-laparoscopic cholecystectomy biliary strictures: Long-term outcome in a multicenter study. Gastroenterol Clin Biol 2006, 30(1):124-129.

6. Misra S, Melton GB, Geschwind JF, Venbrux AC, Cameron JL, Lillemoe KD: Percutaneous management of bile duct strictures and injuries associated with laparoscopic cholecystectomy: a decade of experience. J Am Coll Surg 2004, 198(2):218-226.

7. Lillemoe KD, Melton GB, Cameron JL, Pitt HA, Campbell KA, Talamini MA, Sauter PA, Coleman J, Yeo CJ: Post operative bile duct strictures: management and outcome in the 1990s. Ann Surg 2000, 232(3):430-441.

8. Sikora SS, Pottakkat B, Srikanth G, Kumar A, Saxena R, Kapoor VK: Postcholecystectomy benign biliary strictures - long-term results. Digest Surg 2006, 23(5-6):304-312.

9. Laasch HU, Martin DF: Management of benign biliary strictures. Cardiovasc Intervent Radiol 2002, 25(6):457-466.

10. Pottakkat B, Vijayahari R, Prakash A, Singh RK, Behari A, Kapoor VK, Saxena R: Factors predicting failure following high bilio-enteric anastomosis for after latrogenic Biliary Injury induced by cholecystectomy benign biliary strictures. J Gastrointest Surg 2010, 14(9):1389-1394.

11. Costamagna G, Shah SK, Tringali A: Current management of postoperative complications and benign biliary strictures. Gastrointest Endosc Clin N Am 2003, 13(4):635-648

12. Chaudhary A, Negi SS, Puri SK, Narang P: Comparison of magnetic resonance cholangiography and percutaneous transhepatic cholangiography in the evaluation of bile duct strictures after cholecystectomy. Br J Surg 2002, 89(4):433-436.

13. Tian FZ, Tan LJ, Luo H, Li KZ, Wang Y, Li DX: Progressive balloon dilatation following hepaticojejunostomy in the treatment of traumatic biliary strictures. Chin J Dig Surg 2009, 8(1):18-20.

14. Zepeda-Gómez S, Baron TH: Benign biliary strictures: current endoscopic management. Nat Rev Gastroenterol Hepatol 2011, 8(10):573-581.

15. Bismuth $H$, Majno PE: Biliary strictures: classification based on the principles of surgical treatment. World J Surg 2001, 25(10):1241-1244. 
16. Rodriguez-Montes JA, Rojo E, Martin LG: Complications following repair of extrahepatic bile duct injuries after blunt abdominal trauma. World J Surg 2001, 25(10):1313-1316.

17. Vinay K: Kapoor: bile duct injury repair: when? what? who? J Hepatobiliary Pancreat Surg 2007, 14(5):476-479.

18. Club TSS: A prospective analysis of 1518 laparoscopic cholecystectomies. N Engl J Med 1991, 324(16):1073-1078.

19. Karvonen J, Salminen P, Grönroos JM: Bile duct injuries during open and laparoscopic cholecystectomy in the laparoscopic era: alarming trends. Surg Endosc 2011, 25(9):2906-2910.

20. Nealon WH, Urrutia F: Long-term follow-up after bilioenteric anastomosis for benign bile duct stricture. Ann Surg 1996, 223(6):639-648.

doi:10.1186/1471-230X-13-70

Cite this article as: Luo et al:: Progressive balloon dilatation following

hepaticojejunostomy improves outcome of bile duct stricture after

iatrogenic biliary injury. BMC Gastroenterology 2013 13:70.

\section{Submit your next manuscript to BioMed Central and take full advantage of:}

- Convenient online submission

- Thorough peer review

- No space constraints or color figure charges

- Immediate publication on acceptance

- Inclusion in PubMed, CAS, Scopus and Google Scholar

- Research which is freely available for redistribution 